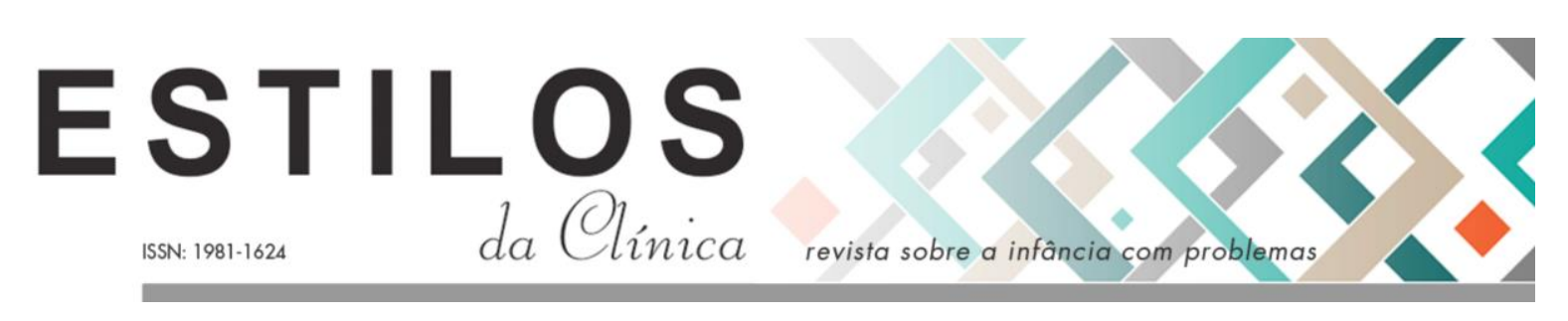

DOI: https://doi.org/10.11606/issn.1981-1624.v24i2p329-341.

\title{
Artigo
}

\section{Autismos: Uma estrutura de existência e a legitimidade dos sujeitos}

\author{
Lucas Silva Romano; João Luiz Leitão Paravidini; Caio César Souza Camargo Próchno
}

Resumo. Este artigo visa estender a noção de estrutura do sujeito - entendida como efeito de um encontro contingencial, marcado pela ruptura e fadado à repetição - para o campo dos autismos. Apresenta-se uma investigação do processo que leva à constituição do falante, associada à hipótese de que o autismo evidencia fortes indícios de um processo de subjetivação particular. Tal proposição incide sob a direção do tratamento, como um modo de abordar os sujeitos autistas com uma presença de demanda calculada.

Palavras-chave: autismo; estrutura; sujeito; psicanálise; constituição.

\section{Autismos: Una estructura de existencia y la legitimidad de los sujetos}

Resumen. Este artículo pretende extender la noción de estructura del sujeto - entendida como efecto de un encuentro contingencial, marcado por la ruptura e condenado a la repetición - en los casos autismos. Se presenta una investigación del proceso que lleva a la constitución del hablante, asociada a la hipótesis de que el autismo evidencia fuertes indicios de un proceso de subjetivación particular. Esta proposición se refiere bajo la dirección del tratamiento, como un modo de abordar a los sujetos autistas con una presencia de demanda calculada.

Palabras clave: autismo; estructura; sujeto; psicoanálisis; constitución.

\section{Autism: A structure of existence and the legitimacy of subjects}

Abstract. This article aims to extend the notion of the structure of the subject - understood as the effect of a contingent meeting, marked by the rupture and bound to the repetition - to the field of autisms, articulating it to its impact in the psychoanalytic approach of the people with autism. We present an investigation of the process that leads to the constitution of the speaker, associated with the hypothesis that the autism shows strong indications of a particular subjectivation process. Such a proposition focuses under the direction of treatment, as a way of approaching autistic subjects with a presence of calculated demand.

Keywords: autism; structure; subject; psychoanalysis; constitution.

1. Mestrando em Psicologia na Universidade Federal de Uberlândia, Uberlândia, MG, Brasil. E-mail: lucassilvaromano@gmail.com

2. Psicanalista, Professor Associado da Universidade Federal de Uberlândia, Uberlândia, MG, Brasil. Email: paravidini@ufu.br

3. Professor Titular do Instituto de Psicologia da Universidade Federal de Uberlândia, Uberlândia, MG, Brasil. E-mail: caio.prochno@ufu.br 
A

s manifestações singulares de pessoas autistas vêm historicamente fazendo frente à sua apreensão pelas áreas de conhecimento. Seus modos particulares de configurar o campo do Outro, do semelhante e dos objetos são traços que, somados às características observáveis de isolamento, estereotipias e distúrbios de linguagem, tradicionalmente tem remetido a condição ao prisma multifacetado das deficiências. Em decorrência disso, colocam-se formas de abordagem que se concentram exclusivamente numa melhor adaptação destas pessoas ao meio. Objetivo que tem como impasse a possibilidade de ocultação do sujeito humano, cuja especificidade é precisamente ser, de modo incontornável, atravessado pela linguagem.

Desde que a condição autística foi isolada pela primeira vez por Leo Kanner, em 1943, é possível identificar, no campo da Psicanálise, uma significativa produção pioneira de narrativas teóricas que buscam apreender o autismo em sua vertente fenomenológica (Bettelheim, 1967/1987; Mahler, 1968/1973; Tustin, 1972/1977; Meltzer, 1975/1980; R. e R. Lefort, 1980/1984). Neste contexto, como aponta Maleval (2017), as quatro grandes abordagens psicanalíticas do autismo infantil têm em comum a intuição de que se trata da patologia mais arcaica.

Para Bettelheim (1967/1987), trata-se da angústia mais extrema. Este autor considera que o sujeito autista está engajado num trabalho constante para atenuar a sua angústia. Para Mahler (1968/1973), o autismo se refere à regressão libidinal mais profunda. Nesta concepção, o autismo é tomado como uma fixação ou regressão à primeira fase da vida extrauterina. Tustin (1972/1977), por sua vez, considera que a criança autista está fechada em uma capsula protetora, no interior da qual a atenção está concentrada em sensações autogeradas. As construções da autora baseiam-se na hipótese da fantasia mais catastrófica. Já para Meltzer (1975/1980), o sujeito autista funciona na bidimensionalidade, pois ele não seria angustiado, nem estaria se defendendo, além de não possuir atividade propriamente considerada mental. Ele se situaria no grau zero da transferência, configurando-se como um ser arcaico por excelência. Para Meltzer (1975/1980), no autismo, trata-se do funcionamento mais problemático do self.

Rosine e Robert. Lefort (1980/1984) baseiam-se no tratamento de uma criança autista de trinta meses que foi encontrada no início dos anos 1950, por meio da qual lançam suas construções teóricas e buscam estender a noção de estrutura na apreensão dos fenômenos de linguagem, isolamento, estereotipias, e as relações de objetos que se colocam no autismo infantil. As principais noções que se destacam das pesquisas do casal Lefort remetem às primeiras intuições conduzidas pelas experiências iniciais com a criança autista que foi tomada como objeto de seus estudos. As bofetadas que Marie-Françoise dá-lhes na primeira sessão, testemunham que "o mundo é para destruir, ou destruí-la", levando o casal a apreender a estrutura do autismo como sendo dominada por uma relação destrutiva pelo Outro (Maleval, 2017).

Para os Lefort (1980/1984), o Outro do autista seria um Outro real, sem furo, impossibilitando toda e qualquer relação transferencial. Além disso, não haveria alienação significante, o que problematiza a divisão do sujeito no campo da linguagem, e confere a primazia do duplo à estrutura autística.

Ao analisar o caráter inovador da leitura dos Lefort (1980/1984) sobre o autismo, Maleval (2017) considera que a predominância do duplo e da pulsão de destruição, principais noções de suas pesquisas, são demasiado amplas e insuficientes para captar a estrutura do autismo. 
Todavia, a genialidade do casal Lefort está justamente na possibilidade lançada por eles em sua empreitada apreensiva do autismo, que consiste em concebê-lo na dimensão de uma estrutura do sujeito.

A partir deste enfoque, isto é, da possibilidade de propor um princípio organizador dos fenômenos no autismo sob a perspectiva de uma estrutura do sujeito, trabalharemos neste artigo as seguintes questões: Por que pensar o autismo como uma estrutura de existência? Qual o impacto desta concepção no campo da abordagem psicanalítica de pessoas autistas?

\section{Por que uma estrutura?}

É notável que um ponto que salta do percurso de apreensão teórica do autismo é a constatação de que a condição está presente desde o nascimento do bebê, que passa a manifestar as características do quadro até mesmo antes dos doze meses de idade.

Com o tempo, certos sinais fazem suas primeiras aparições (desejo de solidão, vontade de imutabilidade, estereotipias e distúrbios de linguagem ou ausência mesma da fala) em articulação com um sinal maior que nos parece fundamental: a dificuldade em estabelecer relações com o Outro, isto é, com o campo propriamente simbólico em que se inscrevem os ordenamentos da linguagem e da cultura. A particularidade deste aspecto se encontra no que podemos chamar de nascimento do sujeito, concebido como um efeito decorrente da forma como cada indivíduo equaciona a experiência simbólica de sua relação com o Outro numa cadeia significante.

Em outras palavras, o Outro, como o registro em que se ancora a realidade psíquica na dimensão de um enquadre estrutural, convoca, pelos modos de posicionamento do indivíduo em seus constantes remetimentos simbólicos, aquilo que supõe uma estrutura, isto é, o sujeito (Miller, 2013). Neste sentido, será possível estender a noção de estrutura, tal como trabalhada em psicanálise, para o campo do autismo, pois isto nos permitirá acessar a dimensão conflituosa desta proposição, uma vez que a noção de estrutura supõe, fundamentalmente, um ordenamento simbólico, seja ele qual for.

Como demarca Kauffmann (1996), ao fazer uma análise das abordagens psicanalíticas pioneiras do autismo, a posição de Lacan diante de todas as tentativas anteriores que pareciam buscar reduzir o autismo a denominadores comuns, é a mais firme possível. Nele a dualidade constantemente afirmada por Freud ${ }^{1}$ culmina na distinção de duas estruturas, a do gozo e a do desejo, colocando em jogo três registros rigorosamente heterogêneos: real-simbólicoimaginário, cujo balizamento instaura uma clínica diferencial entre neurose, psicose e perversão.

Essas categorias, prossegue Kauffmann (1996), permitem então explorar a perturbação da linguagem em ação no autismo sem recorrer à psicogênese, com o biologicismo que inevitavelmente a sustenta. Em consequência, o nascimento do sujeito deixa de estar ligado a uma fase do desenvolvimento em que a fala (em sua dimensão de veículo do campo simbólico e cultural), graças a uma maternagem suficientemente boa se consolidaria, para remeter a um tempo lógico marcado pela ruptura e fadado à repetição.

Refere-se às proposições de Freud a respeito da pulsão auto-erótica, presentes em seu texto "Sobre o narcisismo: uma introdução" de 1914. Kauffmann (1996) aborda este texto para apresentar como as primeiras teorizações sobre o autismo, no campo da psicanálise, o concebiam articuladas à existência de duas libidos propostas por Freud - a libido do eu e a libido do objeto, cada uma implicando uma escolha de objeto segundo o tipo narcísico ou o tipo por apoio. 


\section{As Estruturas clínicas como registros de existência}

Em 1933, ao fazer o uso da metáfora do cristal, Freud apresenta a noção de um revelador antropológico do psiquismo, permitindo-nos pensar o adoecimento psíquico como uma espécie de bússola que orienta a apreensão dos modos como o sujeito se enreda em sua existência:

(...) Onde ela mostra uma brecha ou uma rachadura, ali pode normalmente estar presente uma articulação. Se atirarmos ao chão um cristal, ele se parte, mas não em pedaços ao acaso. Ele se desfaz, segundo linhas de clivagem, em fragmentos cujos limites, embora fossem invisíveis, estavam predeterminados pela estrutura do cristal. Os doentes mentais são estruturas divididas e partidas do mesmo tipo (Freud, 1933 [1932]/1994, p.64).

O fundamental desta analogia, porém, direciona-se para uma questão ontológica: Como se constitui o sujeito e como se insere numa determinada lógica de funcionamento?

No enquadre mitológico da subjetividade, supõe-se que a inscrição do sujeito no universo simbólico da linguagem (grande Outro) se dá por meio de um processo de simbolização em que um elenco de significantes se faz presente numa sequência de operações lógicas, a partir do momento em que o infans é tomado pelos cuidados básicos de um outro primordial. Trata-se do estabelecimento de um repertório de ações que promovem à criança sensações de satisfação e prazer, articuladas às experiências simbólicas de frustração, privação e castração. Estas noções partem da releitura de Jacques Lacan sobre um dos principais fundamentos da Psicanálise - o Complexo de Édipo.

Em 1957, no Seminário - Livro V, Lacan (1999) apresentará o processo de simbolização do Édipo em três tempos lógicos, cujo cerne se concentra na articulação de duas operações fundamentais para o nascimento do sujeito - as operações significantes de alienação (S1) e separação (S2), que dizem do modo pelo qual o infans recebe o impacto da linguagem em seu corpo.

Inicialmente, o que Lacan (1999) destaca é que não há sujeito se não houver um significante que o funde. $\mathrm{O}$ bebê se encontra assim inserido na primeira relação de realidade desenhada entre ele e a pessoa que lhe exerce a função de mãe. É desse modo que ele experimenta seus primeiros contatos com o meio vivo e é inserido numa cadeia significante de tempos lógicos. Nesta posição, o que a criança busca é satisfazer o desejo da mãe, pois se percebe como objeto de gozo dela, ao passo que, simultaneamente, vai se identificando especularmente com aquilo que é objeto de desejo dela. A criança, então, revela depender do desejo da mãe, da primeira simbolização da mãe como tal e de mais nada. Esta primeira experiência de satisfação estabelece o gozo como ponto de inserção do sujeito no aparelho significante, e se configura como o tempo da alienação (S1).

No primeiro tempo, descrevem Lopes e Bernardino (2011), cada parte do corpo do bebê vai recebendo inscrições psíquicas, como se a mãe fosse desenhando no corpo dele. Estes cuidados o inserem no circuito pulsional, por meio do qual a noção de desejo é instaurada pela via da satisfação e do movimento que a mãe faz ao transformar a necessidade física e biológica do bebê (vivida com angústia por sua incapacidade prematura de simbolização) em demanda; demanda esta, que primitivamente localiza o outro (semelhante) como o detentor da solução. 
Como coloca Vorcaro (2016), sobre o movimento que o agente materno opera na apreensão das necessidades físicas do infans, a mãe interpreta a descarga tensional da criança como uma demanda à satisfação a que responde por meio da oferta do objeto (alimento) que visa a satisfazer a necessidade.

\begin{abstract}
Estabelece-se assim o registro de uma matriz simbolizante mínima, na medida em que [o agente materno] alterna presença (a sua presença coincide com a do objeto de satisfação que ele traz) e ausência (que a criança manifesta pela descarga da tensão de seu mal-estar). A possibilidade da presença está antecipada na demanda que requer o objeto, e a possibilidade da ausência está configurada desde que o objeto esteja presente. (...) ao posicionar-se como endereço dessas demandas, o outro materno exerce sua função, respondendo-lhe mesmo com sua ausência, desde que retome o jogo com sua presença, para em seguida ausentar-se novamente (Vorcaro, 2016, p.8).
\end{abstract}

É por meio desta primeira simbolização que a criança desvincula sua dependência efetiva do desejo materno da pura e simples vivência dessa apetência e alguma coisa se institui, sendo subjetivada num nível primário e primitivo. Instala-se, para a criança, a questão: "O que ela deseja?"; que por sua vez, poderá mais tarde ser lida como: “O que o Outro deseja?". Estamos, aqui, falando da passagem para um outro tempo, o tempo do significante separação (S2); isto é, separação do encadeamento que compôs o primeiro tempo. O ponto essencial, entretanto, é que, a partir da primeira simbolização em que se afirma o desejo da criança, se esboçam todas as complicações posteriores do processo de simbolização por completo, na medida em que seu desejo passa a ser o desejo deste outro primordial.

A possibilidade de separação é conduzida sob a instauração metafórica da lei, ou o que Lacan (1999) chamou de operação de introdução do Nome-do-Pai. Este último, além de impedir a fusão da díade primária, instaura a inscrição de possibilidades significatórias, ao representar a lei do falo, aquela que barra o gozo. Essencialmente, Lacan (1999) afirma que o pai não é um objeto real, mas uma metáfora. Para ele, a via simbólica é a via metafórica, apresentada pela ideia de um significante que surge no lugar de outro significante. O lugar que o significante Nome-do-Pai vai substituir é o do primeiro significante introduzido na simbolização primária, o significante materno. E é na medida em que o Nome-do-Pai substitui o acesso ao gozo desenfreado, agenciado pela mãe, que se produz o resultado comum da metáfora.

Nesta esteira do processo de simbolização, o nascimento do sujeito se coloca como o efeito desta série de encontros contingenciais em que o real do ser se depara circunscrito e imerso em um campo simbólico que vitaliza e estimula seu imaginário, colocando em jogo um ciframento a alteridade. Vorcaro (1999) afirma que o desejo oferecido ao balizamento do sujeito na experiência do discurso sustentado pelo agente materno tem vigência no intervalo entre estes dois significantes: o da alienação (S1) e o da separação (S2). Isto porque, é neste intervalo em que o próprio desejo do agente materno está para além do que ela diz, do que ela intima. E é neste ponto de falta, então, que o sujeito se constitui como efeito da fala.

$\mathrm{Na}$ fenda do intervalo significante, o infans deixaria de estar ligado apenas ao sentido que constitui o essencial da alienação, e passaria a se colocar no funcionamento da linguagem, ao articular-se ao objeto $a$ - elemento não significante, que tampona o intervalo significante. Recobrem-se duas faltas na forma lógica da interseção dos elementos comuns ao sujeito: a falta no Outro, aquilo que é impossível à linguagem, ou seja, o desejo, presença de algo que falta na articulação significante, que a fala não pode capturar, e a falta do sujeito que foi amputado de seu ser pelo sentido que lhe foi dado (Vorcaro e Lucero, 2010). 
Os meios utilizados para resolver o conflito que surge do impasse da busca pela satisfação do desejo diante de uma lei que barra, e que representa a superposição da cultura sob a natureza do ser, vão dizer de uma estrutura clínica no processo de subjetivação, de uma forma de funcionamento convocada pela linguagem. Assim, para o bebê, através do apelo à mãe ausente, se introduz com o uso da linguagem (inicialmente um grito de apelo, uma interjeição devido à ausência) uma dimensão que traz na sua essência outras possibilidades de relacionamentos que carregam a marca de reencontros e perdas.

Sumariamente, a partir da frustração imaginária (vivenciadas pelo infans nas experiências de presença e ausência do agente materno, articulada aos objetos de satisfação que representa) e da privação real (ausência do agente materno em detrimento de outros interesses), a criança pode ser simbolicamente castrada, na medida em que seu desejo se torna barrado por uma instância superior, tal como a lei. Ela é, por meio deste processo, introduzida no funcionamento da linguagem, ou no discurso da civilização, pois, a partir do pressuposto de que o pai não é um objeto real, será possível afirmar que a metáfora paterna se associa necessariamente a um operador da cultura com valor de representação, isto é, um lugar no discurso materno que tenha significado para a criança.

Neste contexto, as estruturas clínicas representam três modos distintos de negação da castração, que dizem da dimensão de uma inscrição no registro simbólico. Como aponta Oliveira $(2015)^{2}$, “o que está em jogo neste processo é a inscrição da possibilidade significatória". As neuroses e as perversões se configuram como formas de administrar a relação com a castração, sob a hipótese de que ela se operou. No caso das psicoses, trata-se da hipótese de que a castração não se operou e, além disso, não se inscreveu como possibilidade de significação sendo, portanto, foracluída do processo de simbolização.

Por sua vez, o que caracteriza cada uma destas estruturas são as formas como nelas os sujeitos se posicionam na linguagem a partir do modo como singularizaram a articulação das operações lógicas significantes. Suas especificidades se configuram como formas de administrar a relação com o Outro, que se equaciona nos modos como os sujeitos operacionalizam este trabalho. Sejam, então, pelas fantasias neuróticas, pelos fetiches perversos ou pelos delírios psicóticos.

Desta perspectiva, uma das coisas que especificam a abordagem psicanalítica do sujeito e dos fenômenos a que está remetido é a ideia de que eles não se localizam no campo das patologias, mas no campo das possibilidades legítimas de significação e constituição psíquica. Isto não significa que seja bom ou ruim estar com o funcionamento subjetivo situado numa ou noutra estrutura. Significa apreender que o registro deste funcionamento está remetido a um modo de trabalho psíquico que sustenta uma ontologia.

É neste sentido que a noção de sujeito é tão cara à Psicanálise. Por meio das construções realizadas nos campos da fala e da linguagem, opera-se uma abertura, na experiência psicanalítica, que busca recepcionar o sujeito em sua dimensão de existência, dando espaço às leis de funcionamento que regem sua realidade psíquica, para situar a emergência do desejo. Assim, pensar o autismo numa dimensão de estrutura é operacionalizar uma apreensão no registro das leis que ordenam o funcionamento do sujeito. É antes, supô-lo, dando margem para a abertura, e para o que isso pode nos ensinar.

\footnotetext{
2 Vídeo-aula sobre diagnóstico diferencial. Disponível em: https://www.youtube.com/watch?v=kJmMt_-w3Us. Acessado em: 20/07/2018
} 
Por sua vez, é necessário destacar que existem tantos autismos quanto pessoas diagnosticadas enquanto tal. Ferreira e Vorcaro (2017) também acentuam esta noção ao falarem sobre o emprego do termo autismos, no plural. As autoras destacam que, como Lacan no campo das psicoses, falar de autismos remete às diferentes formas em que condição se apresenta, bem como aos diversos modos de o sujeito se situar, não obstante, uma organização estrutural comum.

Entretanto, pensaremos na criança com autismo típico, como aquela em que a linguagem não ganhou corpo, e só existe, no melhor dos casos, em estado de ecolalia direta ou diferida, sem a menor implicação subjetiva. Desta perspectiva, será possível elencar fortes indícios de que o mecanismo de recusa, tão característico no funcionamento de pessoas que convivem com um quadro de autismo típico, possui estatuto de resposta (Vorcaro e Lucero, 2010) e apoia-se numa escolha de sujeito (Maleval, 2015).

Tais indícios situam-se em torno de pontos centrais, como a ausência de busca pelo outro (semelhante), que pode ser identificada precocemente no bebê que não busca se fazer olhado pela mãe, mesmo diante de toda solicitação que lhe faça. Na presença mínima, quase escassa de linguagem, articulada ao seu uso específico, isto é, sem uma finalidade de comunicação (ausência de busca pelo Outro). E, fundamentalmente, no que Maleval (2017) destaca como uma característica primordial na apreensão dos autismos: a dificuldade do sujeito em abrir mão do gozo vocal para assumir uma posição de enunciação. Do mesmo lado, dispõem-se, também, o uso autêntico que os autistas fazem dos objetos (reais ou pulsionais) tomados como partes de seu corpo.

Todavia, a abordagem psicanalítica dos autismos se deparará nestes pontos com uma confrontação prática e teórica que, por um lado, exige da teoria clássica, concebida para o tratamento dos neuróticos, uma readaptação e, por outro, impõe a necessidade de uma epistemologia do simbólico e da causação do sujeito (Kauffmann, 1996). Deste ângulo, o processo de constituição do falante permite qualificar o autismo como algo além deste limiar, cujo enigma fenomenológico parece ocultar questões constitutivas da realidade humana, evidenciando que o Outro não é um parceiro natural do sujeito (Maleval, 2017).

\section{A Estrutura autística e a sustentação da ontologia}

A partir do pressuposto de que o que está dado como elemento central na identificação dos autismos é a dificuldade do sujeito em estabelecer relações alteritárias, será possível situá-los em um âmbito mais amplo: a singularidade do funcionamento autístico sugere fortemente que suas principais características estão ancoradas em elementos que definem seu próprio processo de subjetivação. Isto implica considerar que as três formas estruturais de equacionar a experiência do Outro servem como parâmetros para identificar no funcionamento autístico eixos de distintas configurações, que podem ser pensadas a partir de uma mesma matriz ontológica em relação às demais, ou seja, o nascimento do sujeito e seu modo singular de equacionar a experiência do Outro.

Se supormos que o processo de simbolização que leva às configurações estruturais específicas do falante não acontece do mesmo modo nos autismos, será possível afirmar que neste processo o sujeito que se constitui é levado a se posicionar de uma determinada forma em relação ao Outro, ensejando uma produção que, mesmo não sendo desejante, evidencia a característica que lhe confere o status de uma modalidade subjetiva própria, isto é, o trabalho 
que é operado para se sustentar ontologicamente. Esta característica encontra-se situada nas formas particulares com as quais os sujeitos autistas configuraram o campo do Outro, do semelhante e dos objetos em seus modos de funcionar. Por esta razão, a questão se direciona para o modo como podemos pensar a constituição dos sujeitos autistas e o que neste processo produz "leis de sobrevivência".

Vorcaro (1999) destaca que as operações de alienação (S1) e separação (S2) nos ensinam que o sujeito do inconsciente nasce nesta incidência do Real sobre o Simbólico, ou seja, no destacamento do intervalo vazio entre os significantes, a partir do qual a metonímia do desejo se põe em perspectiva. Desejo que, como presença de algo que falta na articulação significante, que desliza na fala, mas que ela não captura, se articula do reconhecimento de duas faltas: a do Outro, que introduz ao sujeito a questão mesma do desejo, e àquela pela qual o sujeito responde a esta falta no Outro com sua própria falta, que se faz reconhecer por meio da operação de separação. No autismo ${ }^{3}$, a questão parece se apresentar precisamente neste ponto em que a relação com o outro (semelhante) se engendra na constituição do sujeito.

Podemos delimitar melhor da seguinte forma: o intervalo entre os significantes S1 e S2 parece não acontecer, uma vez que o bebê frequentemente não é, sequer, atravessado pela experiência de alienação no desejo do outro materno. Os sinais clínicos identificados nos processos de investigação demonstram que desde cedo o bebê não responde, por exemplo, à prosódia melodiosa que caracteriza a linguagem do manhês, utilizada pela mãe para lhe capturar a atenção (Laznik, 2013). Neste ponto, Vorcaro (2016) considera a hipótese de que a incidência singular do agente transmissor da ordem simbólica não tenha sido presentificada e capturada nas primeiras relações do autista com o simbólico. Hipótese que vai ao encontro da concepção de Laznik (2013) sobre o autismo.

Para Laznik (2013), o autismo dá nome a um fenômeno estrutural na constituição do sujeito, e sua plena manifestação pode ser considerada como tradução clínica da não instauração de um certo número de estruturas psíquicas que, por sua ausência, só podem acarretar déficits de tipo cognitivo, entre outros. A não instauração destas estruturas se apresenta como uma falha no estabelecimento do circuito pulsional completo, que se opera no estabelecimento do laço pais-criança, fundando o funcionamento do aparelho psíquico. $\mathrm{O}$ estabelecimento deste circuito pode ser pensado como resultado da operação de alienação, em que o infans é inserido por meio da experiência de gozo vivida na relação com o agente materno no primeiro tempo da cadeia significante do processo de simbolização.

Deste ângulo, a questão central no processo de subjetivação dos sujeitos autistas encontrase na articulação do infans com o outro-semelhante. Vorcaro (2016) destaca que a singularidade do desejo articulada no circuito pulsional dos corpos só fará laço social desde que aparelhada pelo Outro, mas o aparelho da linguagem não opera sem o fisgamento pulsional do outro. Para a autora, na articulação da díade mãe-bebê há algo que não se coloca em jogo e que impede a estruturação de um sujeito desejante, qual seja: o falo. Vorcaro (2016) enfatiza que, no caso da resposta autística, é a referência mútua a este termo ausente, mas incidente, que inexiste, pois não haveria a significação do falo para operar a relação entre a criança e o agente materno. No entanto, continua a autora,

Se recorrentemente constatamos que o autista neutraliza ativamente o encontro com o semelhante (outro), evitando-o e esquivando-se dele, este comparece para o autista. Por

Usaremos o termo no singular para nos referirmos ao recorte que propomos, isto é, pensar a questão da estrutura, a partir da forma mais típica do autismo. Usaremos o termo no plural quando nos referirmos ao conjunto das características gerais. 
vezes, o outro-semelhante é imaginarizado como massa indeterminada e anônima, brutal e perigosa. Grande Outro colossal, só pode ser intrusivo demais e, portanto, insuportável (Vorcaro, 2016, p.19).

É neste contexto, então, que Vorcaro e Lucero (2010) defendem a suposição de um estatuto de resposta na recusa do autismo, um índice de presença deflagrado por um modo pelo qual o infans foi conduzido pelo Outro a situar-se numa posição. Esta resposta, para as autoras, implica na solidificação da linguagem: "quando não há intervalo entre S1 e S2, a primeira dupla de significantes se solidifica, se holofraseia" (Lacan, [1964] 1998, citado por Vorcaro e Lucero, 2010).

Na mesma direção, para Maleval (2015), as raras circunstâncias em que o autista engaja sua voz enunciativa, confirmam pela sua não assunção - posto que ele resiste à alienação de seu ser na linguagem, ao reter o objeto de gozo vocal, um estatuto de resposta. As frases espontâneas são holófrases que se caracterizam por capturar em massa o S1 e o S2, atestando que o autista não é totalmente incólume às repercussões do significante em seu ser. Desta forma, o autor nos chama a atenção para tais fenômenos que sugerem fortemente que o autista se enraíza não em um déficit cognitivo, mas em uma escolha de sujeito, mais ou menos consciente, a fim de se proteger da angústia. Vorcaro (2016) destaca, ainda, que:

Deste ponto de vista, mesmo que por retração, o autista responde, fazendo uma operação de linguagem, independentemente da qualidade de sua resposta. Este estatuto de resposta, entretanto, não se configuraria como produção de um sujeito desejante, na medida em que o sujeito está subsumido à estrutura do outro sem se destacar dela (Vorcaro, 2016, p. 16).

Todavia, senão um sujeito desejante, a resposta do autista aponta para o que há de sujeito em suas condutas, isto é o trabalho de se produzir e de se sustentar na experiência do Outro.

\section{O trabalho do sujeito sob o ordenamento de leis}

A hipótese da solidificação dos significantes no processo de simbolização teria como decorrência não só os distúrbios de linguagem, mas todo o trabalho do sujeito para se manter vivo. A inoperância da singularidade do desejo que circula nas primeiras relações da criança com o agente materno impede que ela seja capturada pelo gozo na cadeia significante, em que se operara o estabelecimento do circuito pulsional e a fundação dos processos de pensamento inconscientes. Por conseguinte, a ancoragem simbólica que permitiria ao sujeito experienciar o mundo por meio de uma das três formas estruturais não acontece, situando de modos particulares a relação dos sujeitos autistas com os significantes do mundo que experimentam.

Neste contexto, Daniel Roy (2008/2017) apresenta duas situações emblemáticas com uma criança autista para formular sua hipótese sobre a relação delas com os significantes:

Situação 01:

Gaétan é um menino autista de doze anos, acolhido em um hospital dia. Nós nos interrogamos sobre um momento singular, o de cruzar o limiar da porta. O momento é o seguinte: ao chegar no limiar de uma porta, Gaétan dá dois ou três passos para trás, para poder em seguida cruzar o limiar, mas a manobra não é sempre bem sucedida e algumas vezes lhe é impossível entrar. Eu noto então que se eu pulo o limiar da porta como um poço, então é possível entrar com a mesma manobra, e entrar no cômodo (Roy, 2008/2017, p.1).

Situação 02: 
[Os pais de Gaétan] me explicam como as coisas se passam em casa, isto é, os diversos rituais imutáveis elaborados por Gaétan e seu modo de adaptar-se à casa. (...) alguma coisa de singular aparece, que diz respeito ao modo como G. lida com sua irmã (...). [Eles] me explicam (...) que G. não pode nunca ficar na mesma sala que sua irmã, que é um imperativo categórico, que se não for respeitado, produz um fenômeno que o pai chama de "imitar o tiranossauro" (...). Eu me surpreendo com este fato (...) [os pais] não sabem o porque e estão de acordo comigo que isto seja bastante surpreendente pois, me dizem eles, passam muito tempo (...) explicando a G. que "ele e a irmã são iguais!" (Roy, 2008/2017, p. 2)

Roy (2008/2017) considera a hipótese de que para as crianças autistas os significantes não são tomados como simbólicos, mas reais. Diante da primeira situação, o autor propõe a interpretação de que o atravessamento do limiar é um ato iminentemente simbólico, fundador da diferença dentro-fora. Para a criança autista, esta diferença não se inscreveria simbolicamente, mas retornaria no real. Roy (2008/2017) destaca que neste exemplo o limiar funciona como um verdadeiro abismo, não um abismo físico entre o corredor e a sala do grupo, mas o abismo "real" para Gaétan entre ele-dentro e ele-fora, entre dois estados "significantes.

Na segunda situação, Roy (2008/2017) considera que onde está sua irmã Gaétan não pode estar, pois há apenas um lugar "real" para "o filho de Sr. e Sra. X". Lá onde ele está ela tem que desaparecer, e lá onde ela está é ele quem deve desaparecer. O significante "filho" funciona para Gaétan como real, no lugar onde habitualmente ele encontra um ponto estável em um sistema simbólico, como um lugar que se articula a outros lugares, em diferentes relações. Por exemplo: "filho" se opõe a "adolescente" e "adulto"; "criança" se articula com os significantes "pai" e "mãe" nas relações de filiação. Em um sistema simbólico, "filho de Sr. e Sra. X", é um lugar que pode ser ocupado por a, b, c... ou por "ninguém" (Roy, 2008/2017).

Efetivamente, a ideia central que o autor trabalha em seu texto, e que parece fundamental para nossa discussão é a noção de trabalho do sujeito autista a partir da forma como o mundo é experienciado pela inscrição dos significantes no registro real e não no registro simbólico. Roy (2008/2017) apresenta a ideia da criança autista como um sujeito já em trabalho, e não de um sujeito que vive no caos. Este seria um ponto central na abordagem de pessoas autistas, pois fornece as pistas para rastrear em seu modo de funcionamento, qual o ordenamento, ou qual a articulação simbólica o sujeito já estaria remetido em sua empreitada. A questão nos autismos, assim, vai ao encontro com o que há de singular em cada sujeito e como cada um vai operar as mais diferentes formas de se sustentar ontologicamente.

Para Roy (2008/2017), cada novo significante ou referência se apresentaria como algo inédito na experiência da criança autista, na medida em que não seriam tomados em um sistema conjunto, articulado e simbólico. Isto coloca o sujeito autista em constante trabalho, na produção de formas de anteparo, formas de se proteger e de se preservar nestas relações. Nesta direção, Roy (2008/2017) destaca que para a criança autista o lugar simbólico existe, sendo ele ocupado ou não por um corpo enquanto corpo vivo, e é um lugar que tem efeitos possíveis sobre os corpos vivos que se encontram sob qualquer título que seja tomado sob sua influência. A questão é o ordenamento das leis que regem os diversos lugares simbólicos, as regras de articulação entre eles que se colocam como fixas para a criança autista.

Por sua vez, Roy (2008/2017) nos lembra que o que define uma ordem simbólica são os lugares que se distinguem entre si e que formam os elementos deste sistema; lugares que podem ser esvaziados e ocupados, mas que de todo modo "ordenam" a realidade. A partir 
disto, o autor sistematiza o trabalho do sujeito autista baseado em três aspectos. Primeiramente, haveria sempre elementos diferentes para o autista e estes elementos não se inscreveriam em um sistema conjunto, o que implica que haja sempre algo a responder sobre esta diferença que se inscreve literalmente sobre ele e que deve sustentar à distância através de diversas manobras. Em segundo lugar, os lugares devem sempre ser ocupados, pois todos os significantes que aparecem funcionam como imperativos categóricos. Em terceiro lugar, não há leis que rejam as relações dos significantes entre eles. Por isso, a criança autista tem a tarefa de fazer a lei dos significantes.

As manobras utilizadas para responder a esta diferença que não se inscreve no simbólico incluem os modos particulares de configurar o campo dos objetos. Vorcaro (2016), ao retomar a noção de objeto autístico proposta incialmente por Francis Tustin, em 1970, trabalha a importância deles na abordagem de pessoas autistas. A autora destaca que estes objetos favorecem um movimento de suplência diante da falha estrutural presente na constituição subjetiva, e que podem conduzir à estabilização do quadro. Isto porque, tal como registrou Tustin, os objetos autísticos não são utilizados com referência à função para a qual foram criados, mas, de maneira idiossincrática para cada criança, para quem são completamente essenciais. Trata-se, fundamentalmente, das sensações que o objeto proporciona, e que remetem, por sua vez, às leis simbólicas que foram criadas pelo autista na relação com o objeto particular.

Deste ângulo, a abordagem dos sujeitos autistas para o tratamento e produção do laço social implica uma apreensão dos modos como se enredam em suas experiências, localizando quais as leis o sujeito começou a construir, ao invés de apenas lhe impor uma ordem educativa ou terapêutica exterior (Roy, 2008/2017). Por este caminho, Vorcaro (2016) considera, ainda, a hipótese de que o autista não suporta a incompletude do simbólico, sendo somente suportável no estatuto maciço do real, e aposta na investigação do modo como ele lida com algo que lhe faz alguma exterioridade. Os objetos autísticos que não suportam a pulsionalidade do outro, neste caso, talvez, permitam manter sob controle a permanência do Outro no real (Vorcaro, 2016).

Nesta mesma direção, encontramos tanto em Roy (2008/2017) como em Vorcaro (2016) a ênfase em um aspecto particular na abordagem da criança autista pelo outro-semelhante que contempla uma dimensão da relação do autista com a alteridade. Para ambos os autores será possível abordar a criança autista de uma "certa distância", apresentando-se como um objeto empírico entre outros; um outro despulsionalizado, que dirige uma oferta sem demanda; um outro que não represente nitidamente o grande Outro, isto é, que não compareça em falta, ao demandar; uma posição de presença discreta, ou ainda, uma parte de "vivo" que não seja nem muito ameaçadora nem muito supérflua. Para Roy (2008/2017), isto acontecerá mais frequentemente pelo recolhimento das marcas que o sujeito deixa. Para Vorcaro (2016), talvez haja a possibilidade de introduzir aí algo de simbólico no trabalho da criança, podendo prendê-la numa cadeia significante ao articulá-la a esta.

\section{Considerações Finais}

Uma abordagem que busque apreender estruturalmente os fenômenos presentes nos autismos nos permitirá conceber as questões suscitadas por eles como legítimas, de maneira 
que elas remetam menos à busca por respostas, e mais à necessidade de estar na construção deste caminho com cada sujeito autista.

Trata-se de uma abordagem dos autismos que busque se conduzir pelas questões suscitadas na relação com os sujeitos. Como foi observado, sustentamos a hipótese de que uma modalidade particular no processo de subjetivação opera na constituição dos sujeitos autistas, fazendo-nos lançar na empreitada de abordá-los orientados por uma das principais características que lhes é intrínseca: a dificuldade em estabelecer relações com o Outro. Um Outro que invade, que é demasiado intruso e sem furos. É nesta direção que se faz necessário um cálculo de presença e de demanda daquele que aborda um sujeito autista. Fazer-se presente na relação de modo a dar lugar às manifestações do sujeito sem reivindicá-las de forma direta por meio da fala oralizada, do olhar ou do toque. Trata-se, em última instância, de uma abordagem oblíqua, que tangencia um lugar de presença, mas não invade o espaço do sujeito.

Pensar o significante "autismo" numa condição de estrutura é legitimar suas características funcionais, pressupondo algo comum e ontológico na constituição dos sujeitos que a experienciam, permitindo-se guiar por eles, seja na busca da produção do laço social, seja na condição mesma do tratamento. No caso dos autismos, a demanda de tratamento circunscreve a experiência da angústia em ângulos distintos: por um lado, refletida no trabalho do sujeito autista que se depara com a necessidade de lidar com o Outro. Por outro lado, no acolhimento e suporte à família, de quem o tratamento requer tamanho engajamento.

O fundamental desta discussão, entretanto, centra-se na abertura para a emergência do sujeito que se estruturou no autismo. Talvez possamos considerar com Vorcaro (2016) que a máquina da linguagem despulsionalizada seja um modo possível de nomear o grande Outro do autista. É uma possibilidade legítima, que remete ao modo como o infans foi conduzido pelo Outro a se situar numa determinada posição. Desta forma, o endereçamento à criança autista, a partir de certo "não-saber", preserva o lugar para sua manifestação, dando vez ao sujeito que trabalha e opera a seu modo.

Abordar os autismos na dimensão de uma estrutura de existência confere um impacto na abordagem psicanalítica de pessoas nesta condição, pois isto significa situar a ética do desejo na dialética do encontro com o sujeito e seus modos de se situar. No entanto, se por um lado podemos com a Psicanálise elencar os elementos que permitem individualizar o autismo como uma modalidade de acontecimento subjetivo próprio, por outro lado, como nos fala Maleval (2017), resta ainda isolar as constantes essenciais que constituem esta estrutura original de funcionamento subjetivo desde o início da vida.

\section{Referências}

Bettelheim, B. (1987). A fortaleza vazia. São Paulo: Martins Fontes. (Trabalho original publicado em 1967).

Ferreira, T. Vorcaro, A. (2017). O tratamento psicanalítico de crianças autistas: dialógo com múltiplas experiências. Belo Horizonte, MG: Autêntica.

Freud, S. (1996). A dissecação da personalidade psíquica. In S. Freud, Edição standard brasileira das obras psicológicas completas de Sigmund Freud (J. Salomão, trad., Vol. 22, pp. 63-84). Rio de Janeiro, RJ: Imago. (Trabalho original publicado em 1933[32]). 
Kanner, L. (1943). Autistic disturbances of affective contact. Nervous Child, (2), 217-250. Recuperado de http://mail.neurodiversity.com/library_kanner_1943.pdf

Kaufmann, P. (1996). Dicionário enciclopédico de psicanálise: o legado de Freud a Lacan (V. Ribeiro, trad.). Rio de Janeiro, RJ: Zahar.

Lacan, J. (1999). O seminário, livro 5: as formações do inconsciente, 1957-58. (V. Ribeiro, trad.). Rio de Janeiro, RJ: Jorge Zahar.

Laznik, M.-C. (2013). A hora e a vez do bebê (E.P. Oliveira, trad.). São Paulo, SP: Langage.

Lefort, R., \& Lefort, R. (1984). Nascimento do Outro (A. Jesuíno, trad.). Salvador, BA: Fator Livraria. (Trabalho original publicado em 1980).

Lopes, T. J. S., \& Bernardino, L. M. F. (2011). O sujeito em constituição, o brincar e a problemática do desejo na modernidade. Revista Mal-estar e Subjetividade, 11(1), 369-395. Recuperado de https://www.redalyc.org/pdf/271/27121482014.pdf

Mahler, M. (1973). Psychose infantile. Paris: Payot. (Trabalho original publicado em 1968).

Maleval, J.-C. (2015). Porque a hipótese de uma estrutura autística. Opção Lacaniana - Revista Brasileira Internacional de Psicanálise, 6 (18), 1-40. Recuperado de http://www.opcaolacaniana.com.br/pdf/numero_18/Por_que_a_hipotese_de_uma_estrutura_auti stica.pdf

Maleval, J. -C. (2017). O autista e sua voz (P.S. de Souza Jr, trad.). São Paulo, SP: Blucher.

Meltzer, D., Bremner, J., Hoxter S., Weddell, D., \& Wittenberg, I. (1980). Explorations dans le monde de l'autisme. Paris: Payot. (Trabalho original publicado em 1975).

Miller, J-A. (2013). Jacques Lacan e a voz. Opção Lacaniana - Revista Brasileira Internacional de Psicanálise, 4 (11), 1-13. Recuperado de http://www.appoa.org.br/uploads/arquivos/1611.pdf

Oliveira, M. (2015). Diagnóstico diferencial: patologias ou formas de existência humana? [Video] Recuperado de https://www.youtube.com/watch?v=kJmMt_-w3Us

Roy, D. (2017). O que nos ensinam as crianças autistas (A. L de Almeida e Silva, trad.). In Encontro com a Clínica do Autismo da Escola Brasileira de Psicanálise. (Trabalho original publicado em La Petite Girafe, $\mathrm{n}^{\mathrm{o}}$ 27, Dialogue avec les autistes, Institut du Champ Freudien, 2008).

Tustin, F. (1977). Autisme et psychose de l'enfant. Paris: Seuil. (Trabalho original publicado em 1972).

Vorcaro, A. M. R. (1999). As crianças na psicanálise: clínica, instituição, laço social. Rio de Janeiro, RJ: Companhia de Freud.

Vorcaro, A. M. R. (2016). O tratamento do autismo: notas introdutórias. Analytica: Revista de Psicanálise, 5(9), 04-30. Recuperado de http://www.seer.ufsj.edu.br/index.php/analytica/article/view/2038/1386

Vorcaro, A. M. R. e Lucero, A. (2010). Entre real, simbólico e imaginário: leituras do autismo. Psicol. Argum, 28(61), 147-157. Recuperado

de https://periodicos.pucpr.br/index.php/psicologiaargumento/article/view/19839/19145

Recebido em janeiro/2019 - Aceito em maio/2019. 